\title{
Hubungan Sikap Kerja Berdiri Dengan Keluhan Low Back Pain Pada Pekerja Kasir Luwes Surakarta
}

\author{
Siti Rachmawati ${ }^{1}$, Seviana Rinawati ${ }^{2}$, Esa Luh Tiaswani ${ }^{3}$, Iwan Suryadi ${ }^{4}$ \\ ${ }^{1}$ Program Studi S1 Ilmu Lingkungan FMIPA UNS \\ ${ }^{2}$ Program Studi DIV K3, Sekolah Vokasi UNS \\ ${ }^{3}$ Program Studi DIII Hiperkes dan KK, Sekolah Vokasi UNS \\ ${ }^{4}$ Program Studi Kesehatan Lingkungan Poltekkes Makassar \\ Email : siti.rachmawati@staff.uns.ac.id, sev1ana_er@staff.uns.ac.id, esaluh31@gmail.com, \\ iwansuryadi@poltekkes-mks.ac.id
}

Tanggal Submisi: 21 Maret 2020; Tanggal Penerimaan: 17 November 2021

\begin{abstract}
ABSTRAK
Keluhan Low Back Pain (LBP) merupakan salah satu gangguan muskuloskeletal yang disebabkan oleh aktivitas tubuh yang kurang baik. Sikap kerja berdiri merupakan salah satu penyebab terjadinya keluhan LBP atau nyeri punggung bawah. Tujuan penelitian ini adalah untuk mengetahui hubungan antara sikap kerja berdiri dengan keluhan nyeri punggung bawah pada kasir Luwes Surakarta. Penelitian ini menggunakan metode penelitian analitik observasional dengan pendekatan cross sectional. Purposive sampling digunakan untuk menentukan sampelnya. Sampel terdiri dari 59 kasir. Pengumpulan data dilakukan dengan menggunakan Rapid Entire Body Assessment (REBA) untuk mengukur postur berdiri, dan Keluhan Low Back Pain didiagnosis menggunakan kuisioner Modified Oswestry Low Back Pain Disability Questionaire. Data dianalisis menggunakan Uji Koefisien Korelasi RankOrder Spearman nonparametrik. Hasil penelitian tentang postur kerja berdiri menunjukkan bahwa 23,7\% responden memiliki risiko postur kerja yang rendah dan $76,3 \%$ responden memiliki risiko postur kerja sedang. Sedangkan penelitian tentang nyeri punggung bawah menunjukkan 52,5\% keluhan ringan, 44,1\% keluhan sedang, dan 3,4\% keluhan tinggi. Uji statistik korelasi antara postur kerja berdiri dan nyeri punggung bawah menunjukkan nilai p sebesar 0,000 dengan kekuatan korelasi 0,54. Dengan demikian, sikap kerja berdiri memiliki korelasi yang signifikan dengan keluhan nyeri punggung bawah.
\end{abstract}

Kata Kunci : Sikap Kerja Berdiri, Low Back Pain, Kasir

\begin{abstract}
Low back pain (LBP) is one of the musculoskeletal disorders caused by the poor body activity. Standing work posture is one of the causes of low back pain. The objective of this research is to investigate the correlation between standing occupational posture and low back pain complaint of the cashiers at Luwes Malls of Surakarta Area. This research used the observational analytical research method with cross sectional approach. Purposive sampling was used to determine its samples. The samples consisted of 59 cashiers at Luwes Malls of Surakarta Area. The data of the research were collected by using the Rapid Entire Body Assessment (REBA) method to measure the standing posture, and the Modified Oswestry Low Back Pain Disability Questionnaire to measure the low back pain complaint. They were analyzed by using the nonparametric Spearman's RankOrder Correlation Coefficient Test. The result of the research on the standing occupational posture shows that $23.7 \%$ of the respondents had a low occupational posture risk and $76.3 \%$ of them had a moderate occupational posture risk. Meanwhile, the research on low back pain shows that $52.5 \%$ had a low complaint, $44.1 \%$ had a medium complaint,
\end{abstract}


and $3.4 \%$ had a high complaint. The statistic test on the correlation between the standing occupational posture and the low back pain shows that the p-value was 0.000 with the correlational strength of 0.54 . Thus, the standing occupational posture had a significant correlation with the low back pain complaint. The standing occupational posture had a correlation with the low back pain complaint of the cashiers at Luwes of Surakarta

Keywords : Standing Work Posture, Low Back Pain, Cashier

ISSN 1979-7621 (Print). ISSN 2620-7761 (Online)

DOI 10.23917/jk.v14i2.13608

\section{PENDAHULUAN}

Industri ritel yang terus berkembang tentu tidak lepas dari permasalahanpermasalahan yang timbul akibat pekerjaan yang dilakukan, termasuk masalah penyakit akibat kerja. Salah satu penyakit akibat kerja yang umum terjadi di dunia dan mempengaruhi hampir seluruh populasi adalah penyakit Low Back Pain atau Nyeri Punggung Bawah (Andini, 2015). Low Back Pain menjadi penyebab utama dari gangguan dan keterbatasan aktifitas serta menjadi penyebab absen kerja hampir di seluruh dunia. Delitto et al (2012) menyatakan bahwa Community Oriented Program for Controle of Rheumatic Disease (COPORD) memaparkan angka kejadian nyeri pada daerah pinggang di Indonesia sebesar $18,2 \%$ pada laki laki dan $13,6 \%$ pada wanita. Sedangkan Rina (2013) menyatakan bahwa National Safety Council melaporkan penyakit akibat kerja yang frekuensi kejadian paling tinggi adalah sakit/nyeri pada punggung, yaitu sebesar 22\% dari 1.700.000 kasus. Buchari (2007) menyatakan bahwa penyakit akibat kerja adalah salah satu penyakit yang diderita pekerja dalam hubungan dengan pekerjaan, baik faktor risiko karena kondisi area tempat kerja, peralatan kerja, material yang dipakai dalam bekerja, proses produksi, cara kerja, limbah perusahaan dan hasil produksi.

Low back pain (LBP) yang disebut juga nyeri punggung bawah (NPB) menjadi keluhan yang paling banyak dialami pekerja, kejadian low back pain ini terjadi secara menyeluruh tidak memandang perbedaan umur, jenis kelamin, pekerjaan, status sosial, ataupun tingkat pendidikan. Hal ini pula yang mengakibatkan lebih dari $70 \%$ manusia dalam kehidupannya pernah mengalami low back pain (Anderson, 2007). Delitto et al (2012) menyatakan bahwa prevalensi kejadian Low Back Pain pada masyarakat pekerja khususnya pekerja yang bekerja menggunakan alat-alat produksi dilaporkan sebesar 39\%, sementara pada pekerja yang melakukan pekerjaan secara statis mempunyai prevalen.

Kejadian low back pain pada masyarakat pekerja diakibatkan oleh faktor ergonomi di tempat kerja. Salah satu dari faktor ergonomi tersebut adalah akibat dari sikap kerja. Sikap kerja yang dilakukan secara monoton dengan waktu kerja yang lama akan mengakibatkan perasaan tidak nyaman bahkan kelelahan. Otot yang digunakan untuk bekerja akan tegang secara terus menerus dan mengakibatkan rasa pegal (dull ache). Tubuh hanya dapat mentolerir postur berdiri dalam jangka waktu yang lama pada satu posisi hanya selama 20 menit. Jika lebih dari batas tersebut, perlahan-lahan akan timbul rasa tidak nyaman pada daerah punggung bawah. Selain itu, Low back pain dapat disebabkan oleh berbagai penyakit muskuloskeletal, gangguan psikologis dan mobilisasi yang salah (Susanti dkk, 2015, WHO, 2013).

Penelitian sebelumnya mengenai Low Back Pain sudah pernah dilakukan oleh Susanti, dkk (2015) sebagai akibat dari posisi berdiri lama pada pekerja kasir yang di tunjukan dengan nilai signifikansi $\mathrm{p}=0,013$. Penelitian tersebut membuktikan bahwa terhadap hubungan yang signifikan 
antara posisi berdiri dengan keluhan Low Back Pain. Penelitian juga dilakukan oleh Kusuma dkk (2014) yang mengungkapkan bahwa terdapat pengaruh antara posisi kerja terhadap kejadian Low Back Pain pada pekerja Kampung Sepatu Mojokerto. Dibuktikan dengan hasil uji statistik Chi Square Test sebesar 8,480 dengan Degree of Freedom (df) bernilai 3. Dan Asymp. Sig. (2-sided) memiliki nilai 0,037.

Berdasarkan survei awal yang dilakukan pada pekerja kasir di Luwes Loji Wetan Surakarta, pekerja kasir bagian market di Luwes Loji Wetan Surakarta bekerja dengan posisi berdiri dan statis lebih dari satu jam dengan jam kerja 5-8 jam perhari. Setelah dilakukan perhitungan dengan metode Rapid Entire Body Assisment (REBA), 8 pekerja kasir memiliki skor sikap kerja dengan kategori sedang dan 2 pekerja dengan skor tinggi. Masa kerja para pekerja kasir di Luwes Loji Wetan bervariasi mulai dari 1,5 tahun hingga 20 tahun. Dan setelah dilakukan pengisian kuisioner low back pain, 7 dari 10 pekerja kasir di Luwes Loji Wetan Surakarta merasakan adanya keluhan low back pain atau nyeri punggung bawah.

Tujuan penelitian ini adalah untuk mengetahui hubungan sikap kerja berdiri dengan keluhan low back pain pada pekerja kasir Luwes Surakarta.

\section{METODE PENELITIAN}

Jenis penelitian yang digunakan adalah observasional analitik dengan metode pendekatan cross sectional menggunakan teknik purposive sampling. Cross Sectional merupakan suatu penelitian untuk mempelajari dinamika korelasi antara faktor-faktor risiko dengan efek, dengan cara pendekatan, observasi, atau pengumpulan data sekaligus pada suatu saat (point time approach). Penelitian ini dilaksanakan di Luwes area Surakarta. Populasi pada penelitian ini adalah pekerja kasir sebanyak 89 orang yang kemudian dilakukan inklusi eksklusi menghasilkan 59 orang.

Instrumen penilaian sikap kerja berdiri adalah dengan metode Rapid Entire Body Assessment (REBA). Rapid Entire Body Assessment (REBA) merupakan metode yang digunakan untuk penilaian faktor risiko ergonomi pada seluruh tubuh ketika bekerja. Metode REBA dilakukan dengan cara melakukan penilaian pada badan, leher, punggung, lengan atas, lengan bawah pergelangan tangan, dan kaki. Terdapat 5 tingkatan risiko pada REBA yakni sangat rendah jika skor akhir penilaian REBA sebesar 1, rendah jika skor akhir penilaian REBA sebesar 2-3, sedang skor akhir penilaian REBA sebesar 4-7, tinggi skor akhir penilaian REBA sebesar 8-10 dan sangat tinggi skor akhir penilaian REBA sebesar 11-15. Keluhan Low Back Pain didiagnosis dini menggunakan kuisioner Modified Oswestry Low Back Pain Disability Questionaire.

Pengolahan dan analisis data dilakukan secara deskriptif yaitu analisis bivariat untuk mengetahui hubungan antar variabel. Analisis bivariat dengan cara korelasi spearman.

\section{HASIL DAN PEMBAHASAN}

Seluruh responden berjumlah 59 orang berjenis kelamin perempuan, jenis kelamin perempuan dipilih dikarenakan pekerja kasir dominan berjenis kelamin perempuan. Jenis kelamin perempuan memiliki risiko low back pain lebih besar dari pada pria. Hal ini dikarenakan peran dari hormone estrogen. Wijnhoven (2013) menyatakan bahwa kadar estrogen meningkat pada proses kehamilan dan penggunaan kontrasepsi sehingga mengakibatkan hormone relaxin. Peningkatan hormon relaxin dapat mengakibatkan kelemahan. Hal ini terjadi karena secara fisiologis, kemampuan otot wanita lebih rendah daripada pria pada sendi dan ligamen khususnya pada daerah pinggang NIOSH (1997) mengungkapkan bahwa jenis 
kelamin memberikan pengaruh terhadap tingkat risiko keluhan otot rangka.

Tabel 1. Distribusi Frekuensi Keluhan Low Back Pain Responden

\begin{tabular}{ccc}
\hline Kategori & Frekuensi & Persentase \\
\hline Rendah & 31 & 52,5 \\
\hline Sedang & 26 & 44,1 \\
\hline Berat & 2 & 3,4 \\
\hline Jumlah & 59 & 100 \\
\hline
\end{tabular}

Sumber : Data Primer

Berdasarkan tabel diatas dapat diketahui bahwa sebesar 52,5\% responden memiliki skor keluhan low back pain dengan kategori rendah, 44,1\% memiliki skor sedang dan $3,4 \%$ memiliki skor tinggi. Borenstein dalam Fathoni dkk, (2012) yang menyebutkan hampir dari $80 \%$ penduduk pernah mengalami kejadian low back pain dalam siklus kehidupannya, hal ini dikarenakan keluhan low back pain merupakan keluhan nomor dua yang sering muncul setelah keluhan pada gangguan sistem pernafasan.

Hasil penelitian kali ini diketahui bahwa umur responden dari 20-40 tahun, seluruhnya mengalami keluhan low back pain. Hal ini tidak sesuai dengan pendapat Fathoni, dkk (2012) yang mengemukakan bahwa umur 20-40 tahun tidak berisiko terhadap low back pain karena pada umur tersebut sifat-sifat fisiologis otot masih cukup baik. Hal ini dapat terjadi lantaran masih terdapat faktor-faktor penganggu lainya seperti aktivitas fisik, aktivitas berulang, tekanan yang tidak dikendalikan

Getaran dengan frekuensi tinggi akan menyebabkan kontraksi otot bertrambah. Kontraksi statis ini yang menyebabkan peredaran darah tidak lancar, penimbunan asam laktat meningkat dan akhirnya timbul rasa nyeri otot (Tarwaka, 2014). Peralatan ataupun mesin kasir Luwes Surakarta menunjukan getaran sebesar $0,1 \mathrm{~m} / \mathrm{s}^{2}$, atau dapat dikatakan bahwa peralatan atau mesin kasir Luwes menunjukan adanya getaran. Getaran yang dihasilkan tidak melebihi baku mutu yang ditetapkan dalam Permenkes No. 7 Tahun 2016 yang menyebutkan bahwa baku mutu getaran untuk tangan dan lengan selama 8 jam kerja adalah $5 \mathrm{~m} / \mathrm{s}^{2}$.

Suhu ruangan di area kerja kasir berada pada kisaran rata-rata $24,1^{\circ} \mathrm{C}$, menurut Keputusan Menteri Kesehatan no 1405 tahun 2002 kisaran suhu normal untuk ruang kerja perkantoran berada pada kisaran $18^{\circ} \mathrm{C}-28^{\circ} \mathrm{C}$, oleh karena itu suhu ruangan di area kerja kasir masih dalam batas normal. Tarwaka (2014) menyatakan apabila suhu ruangan kurang dari maupun lebih dari batas normal akan mengakibatkan sebagian energi yang ada dalam tubuh dimanfaatkan oleh tubuh untuk beradaptasi dengan lingkungan tersebut. Apabila hal ini tidak diimbangi dengan pasokan energi yang cukup, maka akan terjadi kekurangan suplai oksigen ke otot. Sebagai akibatnya, peredaran darah kurang lancar, suplai oksigen ke otot menurun, proses metabolisme karbohidrat terhambat dan terjadi penimbunan asam laktat yang dapat menimbulkan rasa nyeri otot.

Responden menggunakan hak sepatu dengan tinggi kurang dari $5 \mathrm{~cm}$, seluruhnya menunjukan adanya keluhan low back pain. Isnain (2013) menjelaskan bahwa penggunaan sepatu hak tinggi berpengaruh terhadap low back pain apabila tinggi hak sepatu lebih dari 5. Keluhan low back pain yang terjadi di penelitian dapat dipengaruhi oleh faktor pengganggu tidak terkendali lainya, atau faktor penggunaan sepatu hak tinggi diluar pekerjaan dan perbedaan penggunaan model sepatu yang tidak diteliti.

Indeks Masa Tubuh (IMT) responden mempunyai kategori normal, dan hasilnya seluruhnya menunjukan keluhan low back pain. Fathoni (2012) mengemukakan bahwa seseorang yang memiliki berat badan berlebih memiliki risiko yang lebih tinggi terhadap timbulnya nyeri pinggang, Keluhan low back pain pada responden dengan IMT normal kemungkinan besar dipengaruhi oleh faktor lain yang tidak 
terkendali, baik faktor pekerjaan maupun faktor diluar pekerjaan.

Pada penelitian ini diketahui bahwa seluruh responden menunjukan masa kerja kurang dari sama dengan 10 tahun dan seluruh responden tersebut menunjukan adanya keluhan low back pain. Umami (2013) menjelaskan bahwa pekerja paling banyak mengalami keluhan nyeri punggung bawah adalah yang mempunyai massa kerja lebih dari 10 tahun. Hal ini dapat dipengaruhi oleh penelitian yang bersifat cross sectional sehingga tidak melihat lebih jauh mengenai masa kerja sebelum bekerja menjadi kasir di Luwes area surakarta, atau rotasi pekerjaan sebelumnya, sebelum menempati posisi pekerjaan sebagai kasir di Luwes area Surakarta.

Seluruh pekerja kasir Luwes Surakarta memiliki durasi berdiri lebih dari 20 menit. Tarwaka (2014) menyatakan bahwa berdiri dengan posisi yang sama selama lebih dari 20 menit dapat mengakibatkan berkurangnya elastisitas jaringan dan mengakibatkan terjadinya ketegangan otot dan menimbulkan rasa tidak nyaman pada daerah punggung. Selain itu, Budiono (2003) menjelaskan bahwa posisi tubuh yang tidak alamiah dan cara kerja yang tidak ergonomis dalam waktu lama dapat menyebabkan berbagai gangguan kesehatan pada pekerja antara lain rasa sakit pada tangan, kaki, perut, punggung, pinggang, dan sebagainya, gangguan gerakan pada bagian tubuh tertentu (kesulitan menggerakan kaki, tangan, leher, atau kepala).

Tabel 2. Hasil Korelasi Sikap Kerja Berdiri dengan Keluhan Low Back Pain.

\begin{tabular}{lcc}
\hline Variabel & Signifikansi & r \\
\hline $\begin{array}{l}\text { Sikap kerja berdiri } \\
\text { dengan keluhan }\end{array}$ & \\
Low Back Pain & 0,000 & 0,544 \\
\hline
\end{tabular}

Sumber : Data Primer

Hasil uji statistik spearman rank antara sikap kerja berdiri dengan keluhan low back pain didapatkan nilai $\mathrm{p}=0,000$ yang mana lebih kecil dari 0,05. Selain itu, didapatkan nilai koefisien korelasi (r) sebesar 0,544.

Berdasarkan hasil uji statistik spearman didapatkan signifikansi hubungan antara sikap kerja berdiri dengan keluhan low back pain pada pekerja kasir di Luwes area Surakarta adalah signifikan dengan nilai $\mathrm{p}$ value $=0,000<\mathrm{p}=0,05$. Serta memiliki arah korelasi positif yang kuat dengan nilai koefisien korelasi $(r)=0,544$. Hasil ini sejalan dengan penelitian sebelumnya oleh Suryadi dan Rachmawati (2020) yang menunjukkan bahwa ada hubungan antara postur kerja dengan keluhan low back pain pada pekerja bagian pengepakan dengan nilai $\mathrm{p}$ value $=0,047$ dan nilai $r=0,282$. Demikian pula dengan penelitian yang dilakukan oleh Rinaldi dkk (2015) bahwa terdapat hubungan yang cukup signifikan ( $\mathrm{p}$ value $=0,002$ ) antara posisi kerja pada pekerja industri batu bata dengan risiko kejadian low back pain.

Susanti dkk (2015) menyatakan bahwa hubungan antara sikap kerja berdiri dan keluhan low back pain disebabkan karena

berdiri dalam waktu yang lama merupakan penyebab paling umum timbulnya ketidaknyamanan kerja dan kelelahan. Oleh karena itu bekerja sambil berdiri dalam waktu lama, akan menimbulkan nyeri pada punggung bawah sekaligus menambah spasme pada otot. Selain itu, Sundari (2011) mengatakan bahwa bekerja dengan sikap kerja tidak alamiah dapat mengakibatkan pergeseran atau penekanan pada bagian penting tubuh seperti organ tubuh, syaraf, tendon dan tulang sehingga keadaan menjadi tidak relaks dan dapat menyebabkan keluhan nyeri.sikap kerja tidak alamiah juga akan menyebabkan beban postural yang berat. Jika beban ini terjadi dalam jangka waktu yang lama, maka akan menimbulkan postural strain yang merupakan beban mekanik statis bagi otot. Kondisi ini akan mengakibatkan kontraksi otot lebih dari $20 \%$ dan mengakibatkan berkurangnya peredaran darah ke otot dan mengurangi aliran darah ke otot sehingga terjadi 
gangguan keseimbangan kimia berupa terjadinya penimbunan asam laktat yang menyebabkan timbulnya nyeri otot.

Sikap kerja berdiri adalah sikap kerja yang posisi tulang belakang vertikal dan berat badan tertumpu secara seimbang pada dua kaki. Bekerja dengan sikap berdiri secara kontinue kemungkinan besar akan terjadi penumpukan darah dan berbagai cairan tubuh pada kaki dan hal ini akan bertambah apabila berbagai bentuk dan ukuran sepatu yang tidak sesuai. Waktu berdiri akan terjadi pergerakan torsi yaitu gerak putar korpus vertebra akibat gaya mekanik yang dipengaruhi oleh diskus intervertebralis 1 sendi faset dan ligamenligamen interspinal. Pembebanan asimetris berkaitan dengan postur tubuh saat aktivitas postur yang seimbang pada waktu berdiri terlalu lama. Dampak posisi lama pada saat berdiri adalah menyebabkan nyeri punggung bawah yang dapat mengganggu kegiatan sehari-hari (Pudjianto, 2001, Rizky, 2007).

\section{SIMPULAN DAN SARAN}

Berdasarkan penelitian yang dilakukan maka diperoleh kesimpulan yaitu terdapat hubungan yang signifikan antara sikap kerja berdiri dengan keluhan low back pain pada pekerja kasir Luwes Surakarta. Saran yang dapat diberikan adalah melakukan peregangan otot setiap 10 menit sekali pada saat sikap kerja sedang berdiri.

\section{UCAPAN TERIMAKASIH}

Ucapan terimakasih diberikan kepada Universitas Sebelas Maret yang telah memberikan dukungan penuh terhadap peneliti dan Luwes Surakarta yang telah memberikan kesempatan dan kesediaannya dalam penelitian ini.

\section{DAFTAR PUSTAKA}

Andini, F., 2015. Risk Factors of Low Back Pain in Workers. J MAJORITY, p. Volume 4 Nomor 1.

Anderson, E. T., 2007. Buku Ajar Keperawatan Komunitas : Teori dan Praktek. Jakarta: EGC.

A.M. Sugeng Budiono. 2003. Bunga Rampai Hiperkes dan Kesehatan Kerja. Semarang : Badan Penerbit UNDIP.

Buchari. Penyakit Akibat Kerja Dan Penyakit Terkait Kerja. Medan: Universitas Sumatera Utara; 2007.

Delitto. A. et al., 2012. Clinical Practice Guidelines Linked to the International Classification of Functioning, Disability, and Health from the Orthopaedic Section. Journal of Orthopaedic \& Sports Physical Therapy, pp. 42(4):A1-A57.

Fathoni, H., Handoyo dan Swasti, K, G. 2012. Hubungan Sikap Dan Posisi Kerja Dengan Low Back Pain Pada Perawat Rsud Purbalingga. Jurnal Keperawatan Soedirman (The Soedirman Journal of Nursing), Volume 7, No.2

Isnain, M. 2013. Hubungan Antara Tinggi Hak Sepatu dan Indeks Massa Tubuh (IMT) dengan Keluhan Nyeri Pinggang Bawah pada Sales Promotion Girls (SPG) Ramayana Salatiga. Jurnal Kesehatan Masyarakat, Volume 2. 
Kusuma, I, F., Hasan, M dan Hartanti, R,I. 2014. Pengaruh Posisi Kerja Terhadap Kejadian Low Back Pain Pada Pekerja Di Kampung Sepatu, Kelurahan Miji, Kecamatan Prajurit Kulon, Kota Mojokerto. Jurnal IKESMA Volume 10 Nomor 1.

NIOSH. 1997. Musculoskeletal disorders and workplace factors: a critical review of epidemiologic evidence for work-related musculoskeletal disorders of the neck, upper extremity, and low back. NIOSH: Centers for Disease Control and Prevention;.

Pudjianto, M., 2001; Diagnosis Banding pada Nyeri Pinggang, Sasana Husada Pro Fisio, Jakarta.

Rina., 2013. Pengaruh Back Exercise Terhadap Pengurangan Nyeri Punggung Bawah Pada Petugas Instalasi Rekam Medik Rsup H.Adam Malik Medan Tahun 2013. Fakultas Kesehatan Masyarakat.Universitas Sumatra Utara. Medan. Skripsi.

Rizki, A, 2007. Gambaran Sikap Kerja Terhadap Keluhan Kesehatan Pekerja Tukang Sepatu di Pusat Industri Kecil (PIK) Menteng Medan Tahun 2007. Fakultas Kesehatan Masyarakat USU, Medan

Rinaldi, E., Wasisto, U., dan Fathra, A, N. 2015. Hubungan Posisi Kerja Pada Pekerja Industri Batu Bata Dengan Kejadian Low Back Pain. JOM Vol 2 No 2

Susanti , N., Hartiyah \& Kuntowato, D., 2015. Hubungan Berdiri Lama dengen Keluhan Nyeri Punggung Bawah Miogenik pada Pekerja Kasir di Surakarta. Jurnal Pena Medika, pp. 60- 70.

Sundari, K. N., 2011. Sikap Kerja Yang Menimbulkan Keluhan Muskuloskeletal dan Meningkatkan Beban Kerja Pada Tukang Bentuk Keramik. Jurnal Ilmiah Teknik Industri, Volume Vol.10, No.1.

Suryadi, I dan Rachmawati, S. 2020. Hubungan Postur Kerja dengan Keluhan Low Back Pain pada Pekerja Bagian Pengepakan PT X Industri Hasil Tembakau. Journal of Vocational Health Studies 03 (2020): 126-130.

Tarwaka, 2014. Ergonomi Idustri, Dasar-Dasar Pengetahuan Ergonomi dan Aplikasi di Tempat Kerja. Surakarta: Harapan Press.

Umami, A., Hartanti, R. \& Dewi, A., 2013. Hubungan antara Karakteristik Responden dan Sikap Kerja Duduk dengan Keluhan Nyeri Punggung Bawah (Low Back Pain) pada Pekerja Batik Tulis. E-journal Pustaka Kesehatan, pp. 2:72-7.

WHO. 2013. Low back pain: Priority medicines for Europe and the world 2013 update $2013 ; 1$.

Wijnhoven, A.H; De Vet, H.C.W; Smit, H.A; Picavet, S.J. Hormonal and Reproductive Factors are Associated with Chronic Low Back Pain and Chronic Upper Extremity Pain in women- The MORGEN Study. Spine. 2006. 31(13) : 1496-1520. 